\title{
Investigation of Torque Characteristics in a Novel Permanent Magnet Flux Switching Machine with an Outer-Rotor Configuration
}

\author{
Weizhong Fei ${ }^{1}$, Patrick Chi Kwong Luk ${ }^{1}$, Dongmin $\mathrm{Miao}^{2}$, and Jianxin $\mathrm{Shen}^{2}$ \\ ${ }^{1}$ School of Engineering, Cranfield University, Cranfield, Bedfordshire, MK43 0AL, U.K. \\ ${ }^{2}$ College of Electrical Engineering, Zhejiang University, Hangzhou, 310027, China
}

\begin{abstract}
This paper comprehensively investigates the torque characteristics of a novel permanent magnet flux switching machine with outerrotor configuration. Due to the nature of severe magnetic saturations in the machine, it is of particular interest to ascertain the extent of impact of the load conditions on the overall torque output as well as its component parts. The frozen permeability techniques are implemented in finite element analysis to segregate the output torque of the outer-rotor permanent magnet flux switching machine into three parts: cogging torque, reluctance torque and permanent magnet torque. Two dimensional finite element analysis is first employed to reveal the effects of phase current amplitudes and angles on those three torque components as well as the overall torque, while the three dimensional finite element analysis is carried out to further uncover the influences of end effects on the torque characteristics of the machine. Finally, experimental tests on a prototype machine are performed to validate the torque characteristic predictions by finite element analysis.
\end{abstract}

Index Terms - Cogging torque, end effect, finite element analysis, frozen permeability, flux switching, magnetic saturation, outerrotor, permanent magnet torque, reluctance torque, torque ripple.

\section{INTRODUCTION}

$\mathrm{T}_{1}$ HE permanent magnet flux switching (PMFS) machine is a less common and relatively new type of permanent magnet (PM) brushless machines comprising a passive and robust salient-pole rotor and a complex salient-pole stator with armature windings and magnets. The earliest single-phase and three-phase PMFS machines date back to 1955 [1] and 1997 [2], respectively. More recently, the PMFS machine has attracted renewed research interests in a host of existing and emerging applications, as their inherent advantages are being recognised, which include high power density, excellent efficiency, low maintenance, high reliability, efficient thermal management, good flux weakening capability and superior controllability [3]. Nonetheless, practitioners have yet found any compelling reason to use PMFS machines in industrial and domestic applications. This is because some of the PMFS machine's key issues such as complex stator structure, high magnet usage, severe magnetic saturations, large stator flux leakage, and high torque ripple, remain unresolved. Various analytical modeling techniques, such as nonlinear magnetic equivalent circuit method [4-6], tooth contour method [7], and Fourier harmonic model [8], have been developed to evaluate the advantages and disadvantages of the PMFS machine. But numerical methods, in particular, finite element analysis (FEA), are still the mainstream modelling techniques. The recent advances in FEA modelling tools are arguably one of the most important reasons for the revived research interests in the PMFS machine. Meanwhile, PMFS machines with various configurations such as the original [9-13], multi-tooth [14,15], multi-magnet [16-18], and hybrid-pole ones [19-21], have been proposed for a wide range of applications, from low

Manuscript received June 25, 2013.Corresponding author: Weizhong Fei (e-mail:w.fei@cranfield.ac.uk).

Color versions of one or more of the figures in this paper are available online at http://ieeexplore.ieee.org

Digital Object Identifier inserted by IEEE power and cost-sensitive domestic appliances to large power and high reliability renewable energy devices, and from the automotive markets to the mission-critical aerospace and defence industries.

Generally, magnetic saturations should be avoided in PM brushless machines as much as possible for high performance applications since they are responsible for increased torque nonlinearity, extra torque pulsations, and further performance deteriorations [22]. However, there will be severe magnetic saturations developed in PMFS machine especially under load conditions as a result of the relatively high magnet volume and small airgap length, together with its rather unique doubly salient structure. This feature particularly could turn into one of the major disadvantages of PMFS machine. The electromagnetic torque generated in the PMFS machine can be segregated into three main parts: cogging torque originated from the PM field energy variations with rotor position, PM torque generated by the interaction between the magnetic fields of PMs and winding currents, and reluctance torque produced by winding inductance alterations with rotor position. Moreover, the three components are heavily coupled with one other due to the severe magnetic saturations in the machine at load conditions. Hence, it is of particular interest to find out the way in which the load conditions influence the cogging torque, PM torque, and reluctance torque as well as the overall torque in the PMFS machine. A fundamental understanding of the unique torque attributes will provide invaluable design guidelines to help address the aforementioned key issues of the PMFS machine.

This paper concerns a comprehensive investigation on the torque characteristics of an outer-rotor PMFS machine, with a particular emphasis on the torque nonlinearity and pulsations. In Section II, the key specifications of the outer-rotor PMFS machine under study is first introduced, and the torque modelling is briefly demonstrated. In Section III, the frozen permeability techniques are introduced and implemented in FEA models to decompose the output torque into cogging 


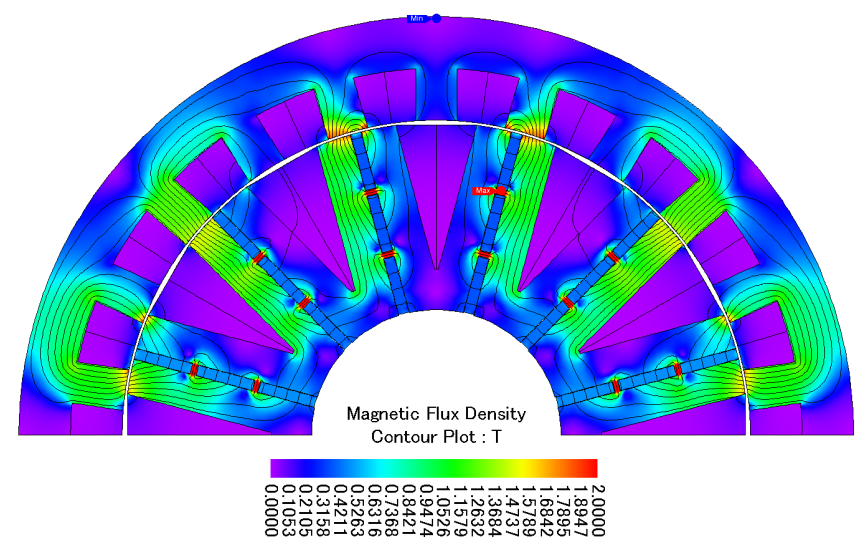

Fig. 1. Open-circuit magnetic flux density distributions of the proposed outer-rotor PMFS machine with flux lines from 2-D FEA results.

TABLE I

MAIN PARAMETERS OF THE OUTER-ROTOR PMFS MACHINE

\begin{tabular}{|c|c|c|c|}
\hline \hline Symbol & Machine Parameter & Values & Unit \\
\hline$p$ & Phase number & 3 & - \\
\hline$N_{s}$ & Stator pole number & 12 & - \\
\hline$N_{r}$ & Rotor pole number & 22 & - \\
\hline$N$ & Coil turn number & 8 & - \\
\hline PM & Magnet material & NdFeB35 & - \\
\hline- & Stator and rotor lamination & 50 ww600 & - \\
\hline$R_{s o}$ & Stator outer radius & 50.0 & $\mathrm{~mm}$ \\
\hline$R_{r o}$ & Rotor outer radius & 65.3 & $\mathrm{~mm}$ \\
\hline$g$ & Air gap length & 0.40 & $\mathrm{~mm}$ \\
\hline$\beta_{p m}$ & Magnet arc width & 2.0 & degree \\
\hline$\beta_{s}$ & Stator tooth arc width & 6.5 & degree \\
\hline$\beta_{r}$ & Rotor tooth arc width & 7.5 & degree \\
\hline$h_{p r}$ & Rotor tooth height & 8.3 & $\mathrm{~mm}$ \\
\hline$h_{y r}$ & Rotor yoke thickness & 6.6 & $\mathrm{~mm}$ \\
\hline$h_{b s}$ & Stator back iron thickness & 4.4 & $\mathrm{~mm}$ \\
\hline$l$ & Machine stack length & 60 & $\mathrm{~mm}$ \\
\hline$k_{p}$ & Winding package factor & $42 \%$ & - \\
\hline$n_{r}$ & Rated rotational speed & 120 & $\mathrm{rpm}$ \\
\hline$U_{d c}$ & DC link voltage & 12 & $\mathrm{~V}$ \\
\hline$I_{r}$ & Rated phase current & $50($ peak) & $\mathrm{A}$ \\
\hline \hline
\end{tabular}

torque, reluctance torque, and PM torque. In Section IV, the influences of load conditions such as phase current amplitudes and angles on the cogging torque, reluctance torque and PM torque as well as overall torque of the proposed PMFS machine are established by 2-D FEA with the frozen permeability technique. Furthermore, the corresponding 3-D FEA is carried out in Section V to reveal the impacts of end effects on the torque characteristics. Section VI presents the prototype machine and experimental results to validate the FEA results, followed by the concluding remarks in Section VII.

\section{OUTER-Rotor PMFS MACHINE AND TORQUE MODELLING}

The research on PMFS machines have been predominately focused on the inner-rotor rotational and the linear types, with relatively little attention given to the outer-rotor one. However, the outer-rotor configuration lends itself to a direct-drive machine particularly due to high torque density and easy mechanical integration. The authors have proposed the outerrotor PMFS machine for its potential applications for vehicle traction [23]. The outer-rotor machine under study, which has been specifically designed for in-wheel light traction applications [12], possesses an elaborate stator of 12 poles with embedded rectangular magnets and concentrated coils and a robust and passive rotor with 22 poles. The PM in each stator pole is radially segmented into three equal pieces by two iron bridges with a width of $1 \mathrm{~mm}$ to promote flux-weakening capability and mitigate magnet eddy current loss. The detailed design and performance optimization of the proposed machine have been reported in [12]. The main design parameters of the machine are given in Table I, whereas the machine opencircuit magnetic flux density distributions with flux lines from 2-D FEA results are depicted in Fig.1. It shows severe magnetic saturations occurring in the iron bridges. Both the cogging torque and phase back electromotive force (EMF) harmonics are minimized during the machine optimization in order to reduce the overall on-load torque ripple. However, the magnetic saturations in the machine would inevitably induce torque nonlinearity and additional torque pulsations.

Generally, the instantaneous electromagnetic torque of an electric machine can be obtained by principle of virtual work as [24]

$T=\left.\frac{\partial W_{c o}(i, \theta)}{\partial \theta}\right|_{i=\text { constant }}=\left.\frac{\partial\left(i^{T} \psi(i, \theta)-W_{f}(i, \theta)\right)}{\partial \theta}\right|_{i=\text { constant }}$

where $W_{c o}(i, \theta), \Psi(i, \theta)$, and $W_{f}(i, \theta)$ are the corresponding coenergy, phase flux linkage matrix and field energy of the machine with a given excitation of phase current matrix $i$ at rotor position $\theta$ respectively. By decoupling the flux linkage and field energy, the instantaneous electromagnetic torque of PMFS machine can be rewritten as

$$
\begin{aligned}
T= & i^{T} \frac{\partial \psi_{p m}(i, \theta)}{\partial \theta}+\frac{1}{2} i^{T} \frac{\partial L(i, \theta)}{\partial \theta} i-\frac{\partial W_{p m}(i, \theta)}{\partial \theta} \\
= & T_{p m}+T_{r}+T_{c}
\end{aligned}
$$

where $\Psi_{p m}(i, \theta), L(i, \theta)$ and $W_{p m}(i, \theta)$ are the phase PM flux linkage matrix, inductance matrix and PM field energy of the machine with certain excitation of phase current matrix $i$ at rotor position $\theta$ respectively, whereas $T_{p m}, T_{r}$, and $T_{c}$ are the corresponding PM torque, reluctance torque, and cogging torque. By inspection of equation (2), one can easily see the instantaneous torque of the PMFS machine is an aggregate of three distinctive parts. This is also true for its torque ripple. However, the machine's inevitable magnetic saturations under load conditions make $\Psi_{p m}(i, \theta), L(i, \theta)$ and $W_{p m}(i, \theta)$ highly dependent on the machine phase current [3]. Thus, the above three torque components are normally tightly coupled so that analytical torque decomposition is practically unfeasible. The recent advent of frozen permeability techniques, which can be easily implemented to obtain the corresponding $\Psi_{p m}(i, \theta), L(i, \theta)$ and $W_{p m}(i, \theta)$, has made the torque segregation possible with numerical methods. As the proposed outer-rotor PMFS machine has essentially sinusoidal back EMF, it is preferred to operate the machine with brushless alternating current (AC) mode for minimum torque ripple [2]. In order to simplify the analysis, it is assumed that the machine is driven by ideal pure sinusoidal currents in this study. 


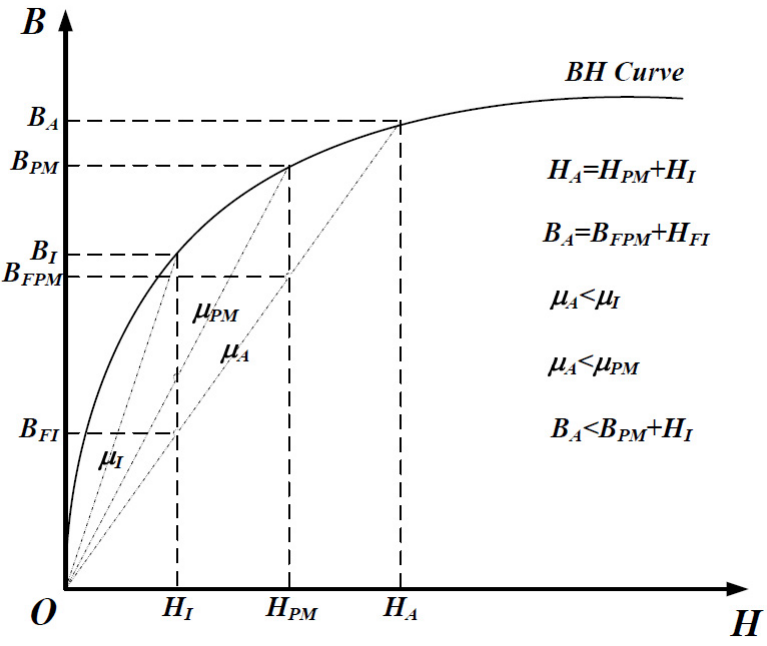

Fig. 2. Principle of frozen permeability technique.for PM machine

\section{Torque Segregation USING Frozen Permeability}

The frozen permeability technique is a method implemented in numerical simulations for segregating the total magnetic flux of electric machines into the corresponding contributions from the different excitations. There are generally two types of excitation sources in PM machine: armature currents and magnets. The principle of the frozen permeability technique for PM machine is depicted and compared with conventional one in Fig. 2. Without using the frozen permeability technique, the resultant flux densities with armature excitation $\left(H_{I}\right)$ and PM excitation $\left(H_{P M}\right)$ are $B_{I}$ and $B_{P M}$ respectively. The resultant flux density $B_{A}$, which is generated by both armature and PM excitations $\left(H_{A}\right)$, is lower than the sum of $B_{I}$ and $B_{P M}$. While with using frozen permeability technique, the permeability $\mu_{A}$ is first derived and stored by field analysis with armature and PM excitations together. The corresponding flux densities $B_{F I}$ and $B_{F P M}$ are calculated linearly based on the frozen $\mu_{A}$ with armature excitation $\left(H_{I}\right)$ and PM excitation $\left(H_{P M}\right)$ respectively. In this case, the resultant flux density $B_{A}$ is equal to the sum of $B_{I}$ and $B_{P M}$, and the armature reaction field and PM field in the machine are decomposed.

It can be perceived that the frozen permeability technique is essential to reveal the influences of magnetic saturations and cross-coupling, as well as to carry out the segregation of the torque components in PM machine. Therefore, the frozen permeability technique has been widely used to investigate the electromagnetic characteristics of PM machine. The simple analytical models with the improved parameters obtained from numerical methods with frozen permeability technique have been widely used to predict the performances of various PM machines [25-27]. Whilst the PM flux linkage and winding inductances at corresponding rotor position and load current can be readily derived based on the individual magnetic flux results, [28-30]. Moreover, the frozen permeability technique is employed to investigate the cause of terminal voltage increase [31] and radial magnetic force density [32] in PM synchronous machine. Meanwhile, the decomposition of the average torque can also be facilitated accordingly $[33,34]$. Furthermore, the virtual work principle and an improved

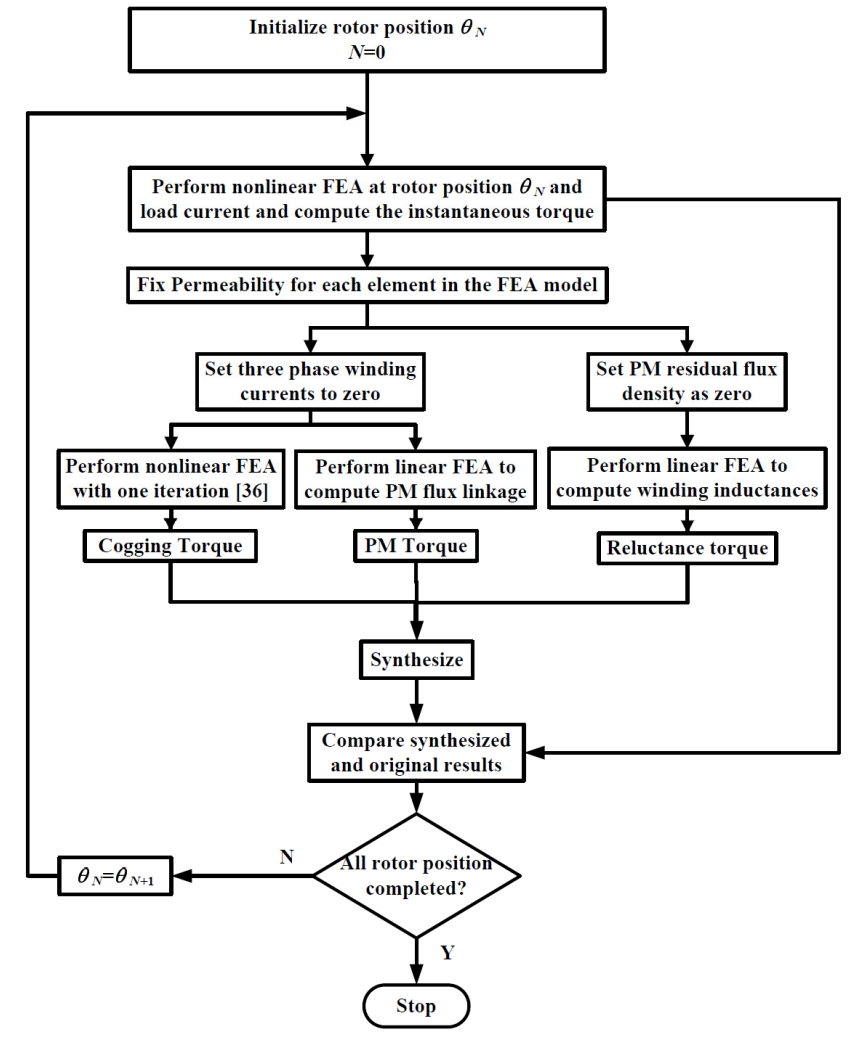

Fig. 3. Flow chart for segregating instantaneous electromagnetic torque using FEA with frozen permeability technique.

frozen permeability method are proposed in order to calculate the on-load cogging torque appropriately [35]. So far, only the average torque segregation has been covered by the literatures. However, the instantaneous electromagnetic torque of the PM machines can be segregated accordingly based on equation (2) with the on-load PM flux linkage, winding inductances, and cogging torque. It is noteworthy that whilst most of the commercial FEA software packages include the frozen permeability technique as an additional feature, only average torque is analysed.

In this study, the frozen permeability technique is employed to segregate the instantaneous electromagnetic torque of the proposed outer-rotor PMFS machine as illustrated in the highlevel flow chart shown in Fig.3. Normally, complete nonlinear numerical analyses involving the nonlinear material magnetic characteristics are crucial to account for the effects of magnetic saturations including cross-coupling effects in the PMFS machine. Therefore, an initial nonlinear FEA solution of the proposed PMFS machine at a given rotor position and load currents is first carried out to obtain the corresponding electromagnetic torque and the resultant permeability in each element of the FEA mesh is derived and stored. Either the PM residual flux density or phase winding currents are set to zero to turn off the corresponding field source in the model so that a corresponding new linear FEA with the stored permeabilities can be performed to determine the corresponding winding inductances or PM flux linkages. So the corresponding onload reluctance torque and PM torque can be subsequently calculated based on equation (2). Furthermore, an additional nonlinear FEA with only PM excitation and single nonlinear 


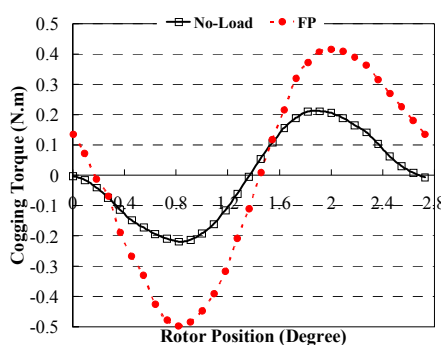

(a)

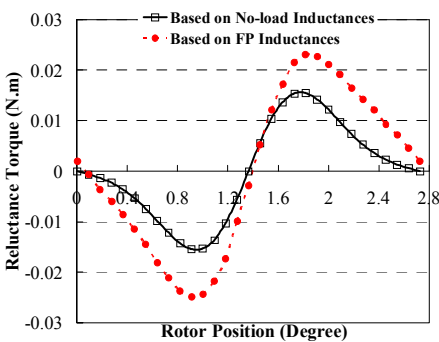

(b)

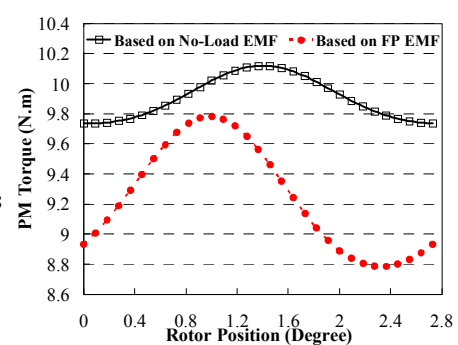

(c)

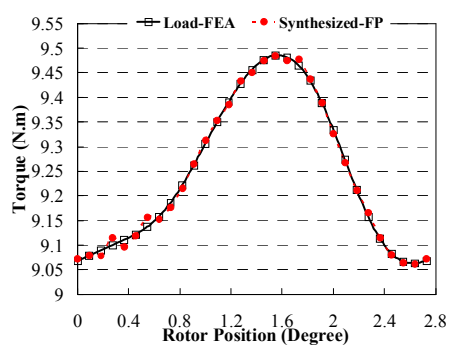

(d)

Fig. 4. Torque features of the proposed PMFS machine from 2-D FEA, (a) cogging torque waveforms from open-circuit and rated load conditions, (b) reluctance torque waveforms based on the inductances from open-circuit and rated load conditions, (c) PM torque waveforms based on PM flux linkages from open-circuit and rated load conditions, (d) torque waveforms under rated condition from nonlinear FEA and synthesis of the segregated torque components.

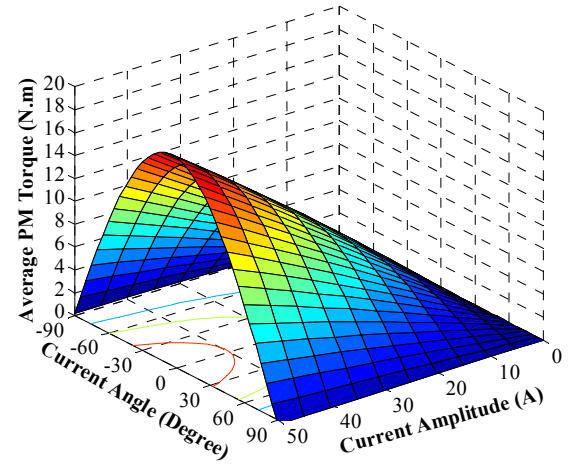

(a)

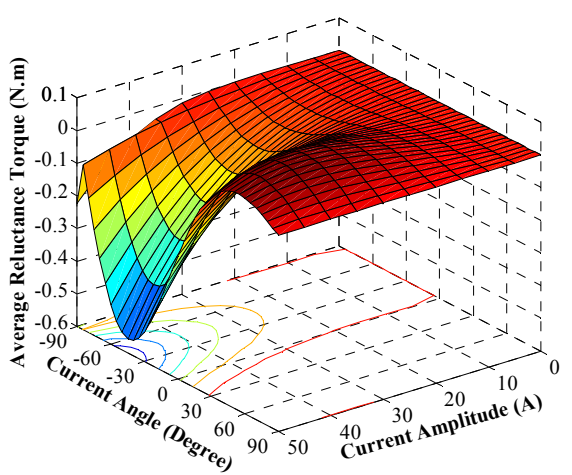

(b)

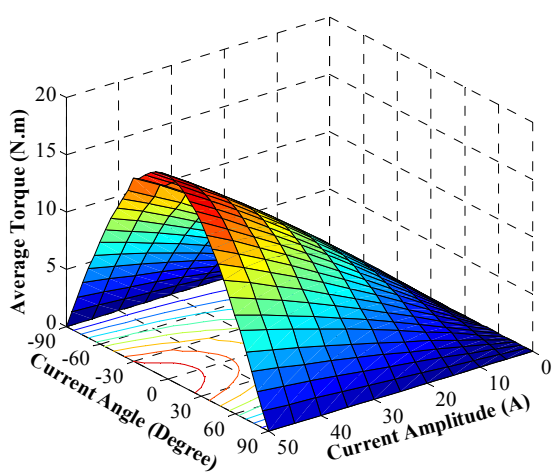

(c)

Fig. 5. Average torque output of the proposed outer-rotor PMFS machine with different current amplitudes and phase angles, (a) average PM torque, (b) average reluctance toqrue, (c) average overall torque.

iteration is carried out based on the stored permeabilities in order to compute the corresponding on-load cogging torque using the virtual work principle [35]. Finally, the resultant torque components from the FEA with the frozen permeability technique, including on-load PM torque, reluctance torque and cogging torque are synthesized to compare with the torque result from the initial nonlinear FEA for validation of the segregation method.

By way of example, torque segregation of the proposed PMFS machine under rated load condition has been carried out by following the analysis flow chart in Fig.3 using 2-D FEA and the results are shown in Fig.4. The on-load cogging torque waveform of the machine under rated load condition is presented and compared with the open-circuit one in Fig.4(a), which implies that the corresponding magnetic saturations would not only bring about extra harmonic components and hence increase the amplitude but also shift the phase of the waveform. The segregated reluctance torque waveform of the machine under rated load condition exhibits larger pulsation than the one calculated based on the open-circuit winding inductances, as shown in Fig.4(b), which implies that the magnetic saturations in the machine enlarge the variations of the inductances.. While Fig.4(c) shows that the segregated PM torque waveform of the machine under rated load condition exhibits not only lower average value (due to torque nonlinearity) but also higher ripple than the one derived from open-circuit PM flux linkages. Finally, Fig.3(d) compares the synthesized and 2-D FEA torque waveforms of the machine under rated load condition. The good agreements between the results thus verify the validity of the proposed segregation method. It can be observed that the magnetic saturations in the machine would impose large influences on each individual torque components. Consequently, it is of particular interest to comprehensively analyse the impacts of magnetic saturations on the torque characteristics of the proposed PMFS machines.

\section{TORque CHARACTERISTICS ANALYSIS}

The average torque and torque ripple of the proposed outerrotor PMFS machine including its three different torque components are comprehensively investigated in this section. The torque characteristics of the machine excited with various current amplitudes (0-50A) and phase angles $\left(-90^{\circ}-90^{\circ}\right)$ are analyzed using 2-D FEA, and the three corresponding torque components of cogging torque, reluctance torque, and PM torque are derived by the proposed torque segregation method. The current phase angles are phase difference between the phase currents and their corresponding phase back EMF. Thus, positive current phase angles mean that the currents are leading the back EMF by corresponding angles so that the flux weakening (demagnetization) is achieved.

The average values of cogging torque in the proposed machine under different load conditions are always zero due to the generation mechanism of this peculiar torque component. Therefore, the comprehensive results of the average PM torque, reluctance torque and overall torque profiles of the proposed machine under different current excitations are obtained and depicted in Fig.5. It is obvious from the figure that the average torque output of the machine is mainly contributed by the PM torque. Consequently, the torque output reaches its maximum at current phase angle of about zero 


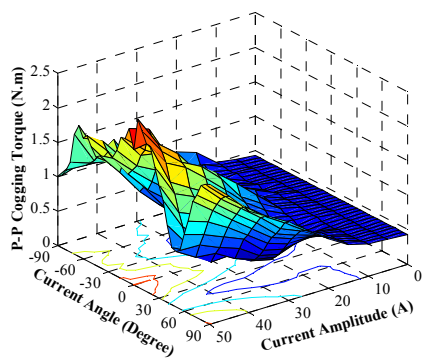

((a)

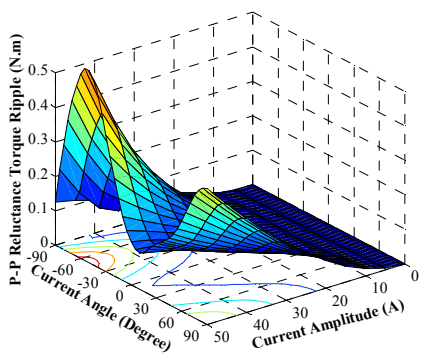

(b)

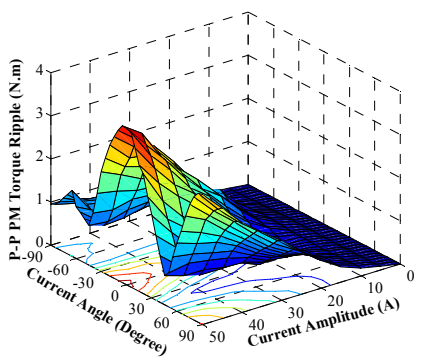

(c)

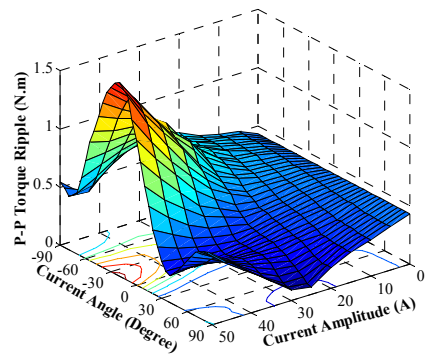

(d)

Fig. 6 P-P torque ripple in different torque components of the proposed outer-rotor PMFS machine with different current amplitudes and phase angles, (a) P-P cogging torque, (b) P-P reluctance torque, (c) P-P PM torque, (d) P-P torque ripple.

degree for each current. The contribution of the reluctance torque is almost negligible for most of the load conditions despite the doubly-salient structure. However, relatively large reluctance torque would be generated to counteract the PM torque in the machine with large current and negative current phase angles.

Furthermore, the peak-to-peak (P-P) torque ripple profiles of the segregated three torque components as well as the overall one in the machine under various loads are compiled and illustrated in Fig.6. It can easily be seen that both the current amplitude and phase angle have considerable influences on the torque ripple characteristics of both the three individual torque components as well as the overall torque, in particular with high current excitations. The P-P cogging torque maintains almost constant with small phase current (below 15A) since magnetic saturations in the machine are relatively mild. As the phase current picks up, magnetic saturations get more severe so that the corresponding P-P cogging torque increases significantly. Moreover, the impacts of phase current on the P-P cogging torque would be most significant with phase angle of around $-90^{\circ}, 0^{\circ}$, and $90^{\circ}$. As the phase current increases, the torque pulsations in both the PM torque and reluctance torque would first gradually rise, and then start to increase significantly as the corresponding magnetic saturations get more severe. On the other hand, the maximum and minimum P-P reluctance torque ripple values can be found at current phase angles of about $-45^{\circ}$ and $15^{\circ}$ respectively for given current amplitude. The P-P PM torque ripple reaches its maximum with the current phase angle of around $0^{\circ}$, and its minimum with the current phase angle of around $-45^{\circ}$ and $45^{\circ}$. On the whole, the torque pulsations which are associated with reluctance torque are much less significant than the ones from cogging torque and PM torque and nearly negligible under low current excitations. Hence, the cogging torque and PM torque ripple are the main contributors of the overall torque ripple of the proposed machine. Despite both the cogging torque and PM torque can potentially exhibit quite remarkable torque ripple, the overall P-P torque ripple profiles of the machine in Fig.6(d) implies that the two torque pulsations can eventually counteract each other to a certain extent. The torque ripple contributions from the reluctance torque would be quite evident with high current excitations. Due to the high current amplitude and large current angle, the flux in the machine is strongly weakened so that the less magnetic saturations occur in the machine. It can be inspected

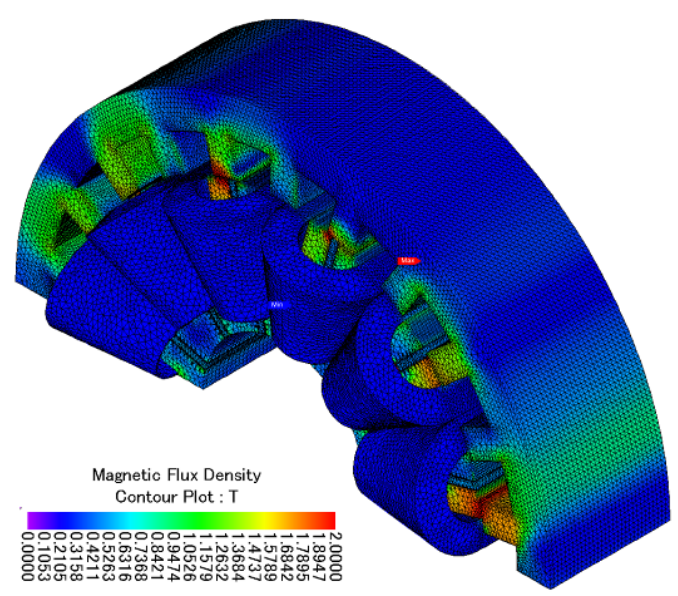

Fig. 6. Open-circuit magnetic flux density distributions of the proposed outer-rotor PMFS machine with meshes from 3-D FEA results.

that the corresponding cogging torque and PM torque ripple with current angle of $45^{\circ}$ and high current amplitude would reach their minimums and they have almost opposite phases. Moreover, the reluctance torque ripple is also very small with this current angle. Overall, the overall torque ripple can reach its minimum at current phase angle of $45^{\circ}$ as large currents are applied. On the other hand, negative current phase angles tend to deliver more severe torque fluctuation than the positive ones partially due to the severe magnetic saturations in the machine due to the flux enhancement. Generally, the torque ripple in the proposed machine has been effectively suppressed by the optimal design.

\section{IMPACT OF END EFFECTS ON TORQUE CHARACTERISTICS}

The end effects in PMFS machine are quite significant and would inevitably deteriorate the machine performance $[4,5]$. The investigations in the previous sections only involve with 2-D FEA without consideration of end effects. In this section, comprehensive 3-D FEA models, which take into account the end effects, are developed to reveal the impacts of the end effects on the torque characteristics of the proposed outerrotor PMFS machine. In order to improve the computational efficiency, only one fourth of the machine is modelled with both the periodic and symmetric boundary conditions. The magnetic flux density distributions of the machine under opencircuit condition from 3-D FEA results are plotted with the 3D meshes in Fig.7, which shows that flux density distributions in the end region differ from the middle one. 


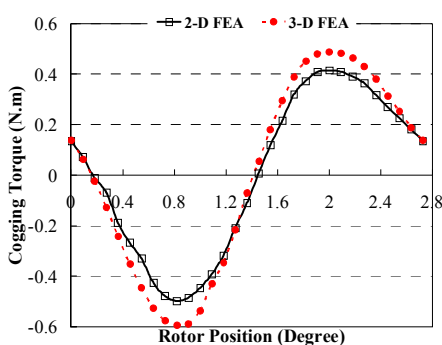

(a)

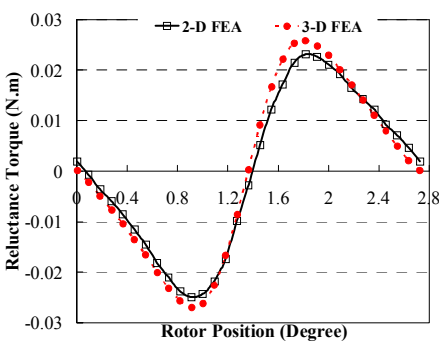

(b)

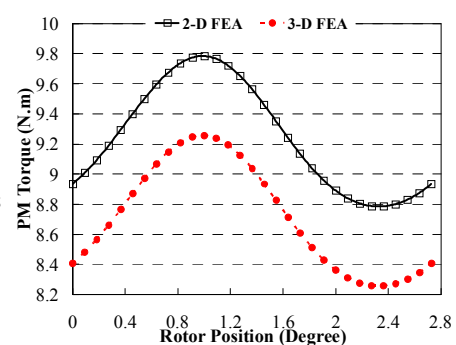

(c)

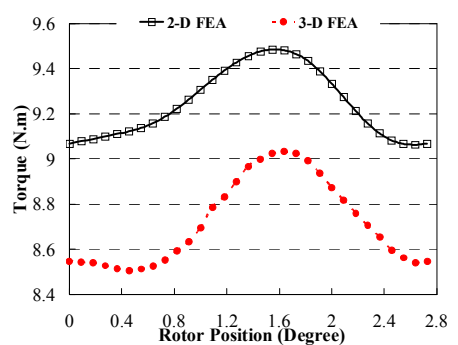

(d)

Fig. 8. Cogging torque, reluctance torque, PM torque, and overall torque of the proposed PMFS machine from 2-D and 3-D FEA, (a) cogging torque waveforms from rated load conditions, (b) reluctance torque waveforms based on the inductances from rated load conditions, (c) PM torque waveforms based on PM flux linkages from rated load conditions, (d) total torque waveforms under rated condition.

The torque segregation of the proposed PMFS machine under rated load condition have been carried out based on 3-D FEA and the corresponding results are compared with the 2-D FEA ones in Fig.8. It shows appreciable differences in the influences of the end effects among the segregated three torque components. The end effects would significantly reduce the average PM torque and hence the overall torque output. On the other hand, the end effects would slightly increase the torque pulsations of each component and hence the overall torque. In order to further explore the impacts of end effects on torque characteristics, the average torque and torque ripple profiles with zero current phase angle and rated current amplitude from 2-D and 3-D FEA results are compiled and depicted in Fig.9. It can be found from the figures that the average torque values from 3-D FEA are nearly $6 \%$ smaller than the 2-D ones. As the current is smaller than $30 \mathrm{~A}$, both the cogging torque, reluctance torque, and PM torque from 3-D FEA results would have slightly higher torque pulsations than the 2-D FEA ones and almost same phase at the current phase angle of $0^{\circ}$. Hence the overall P-P torque ripple values from the 3-D FEA are larger than the 2-D ones. With zero current phase angle and the current exceeding 35A, all the three torque components from 3-D FEA results would still have higher torque pulsations than the 2-D FEA ones but the phase angles of cogging torque and PM torque differ between the 2$\mathrm{D}$ and 3-D FEA results. The cogging torque and PM torque pulsations from 3-D FEA results cancel each other more than the 2-D FEA ones. Therefore the overall torque ripple values from 3-D FEA are smaller than the 2-D ones. Whilst with rated current amplitude, the 3-D FEA P-P torque ripple values are always bigger than the 2-D ones for different current phase angles.

The magnetic fringing effects on the end surfaces of the machine would impose evident impacts on the flux density distributions especially in the axial direction [36], which will bring conventional 2-D FEA challenges to accurately evaluate the torque characteristics. Overall, the end effects in the proposed machine would considerably reduce the average reluctance torque, PM torque and hence overall torque. On the other side, they would increase the torque pulsations of the machine with low current excitations and even could reduce torque ripple with high current excitations. Consequently, the end effects from the 3-D FEA results would only affect the average torque and P-P torque ripple values of the proposed machine but would not vary the profiles of the 2-D FEA results shown in Fig.5 and Fig.6.

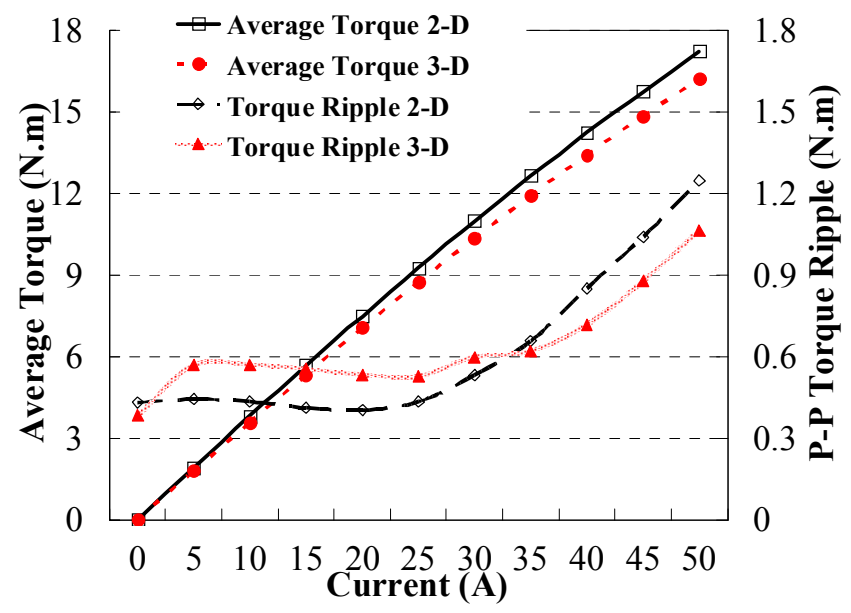

(a)

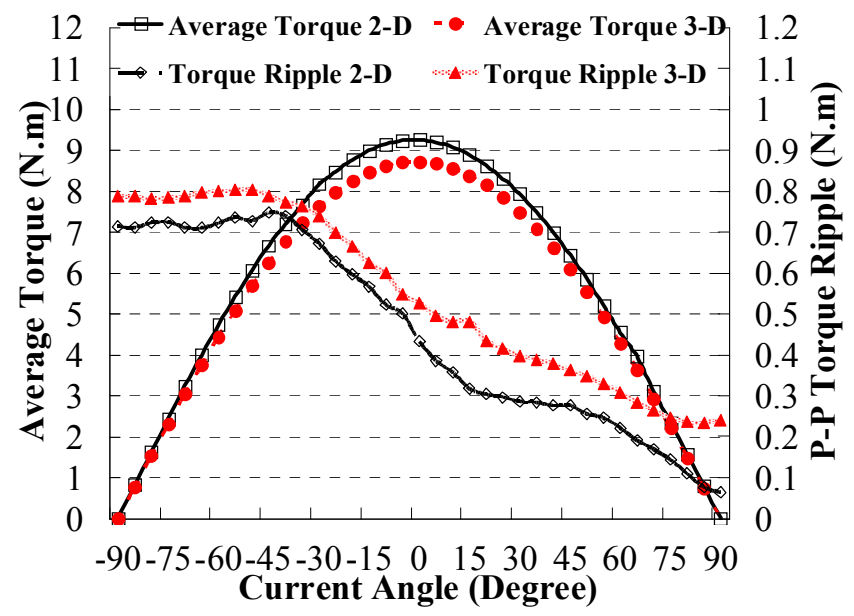

(b)

Fig. 9. The average torque and torque ripple profiles of the machine from 2$\mathrm{D}$ and 3-D FEA, (a) average torque and torque ripple profiles with zero current phase angle, (b) average torque and torque ripple profiles with rated current amplitude.

\section{EXPERIMENTAL VALIDATIONS}

A prototype of the proposed outer-rotor PMFS machine is built for experimental validations. Fig.10 shows the exploded view, actual wound stator, and assembly of the prototype machine. The open-circuit experimental tests are first carried out to obtain the cogging torque and phase back EMF waveforms of the machine. The predicted cogging torque profiles from the 2-D and 3-D FEA models are compared with the measured one in Fig.10(a) and the corresponding P-P cogging torque values are given in Table II. It can be found 


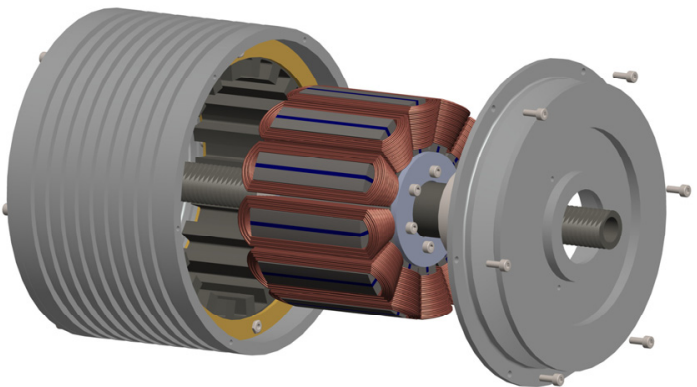

(a)

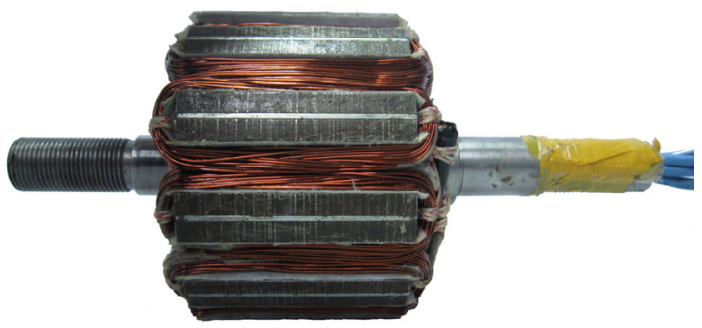

(b)

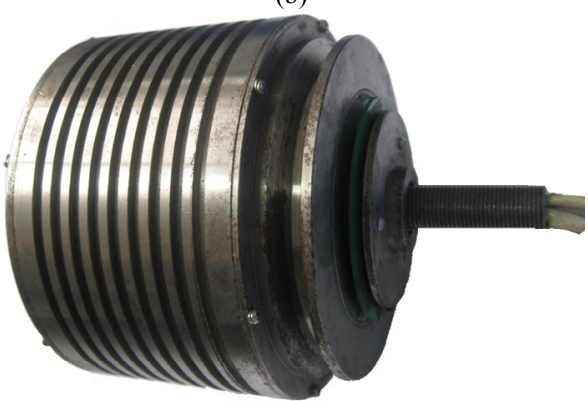

(c)

Fig. 10. Prototype mahine, (a) exploded view, (b) wound stator, (c) assembled machine.

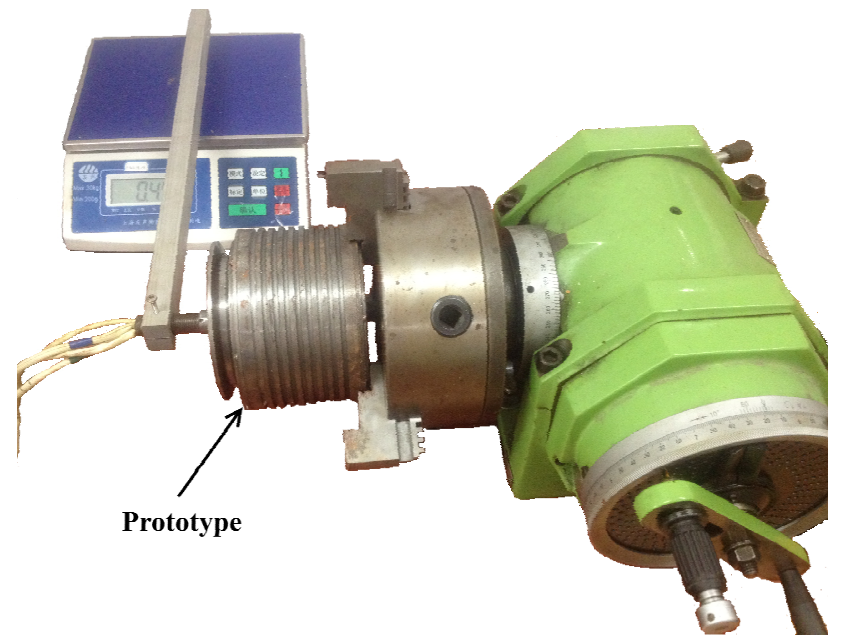

Fig. 11. Experimantal setup for cogging torque measurements of the prototype machines.

that the predicted P-P cogging torque value from 3-D FEA is about 20\% lower than the one from 2-D FEA due to the considerable end effects yet they are almost three times and two times higher than the experimental one respectively. As the cogging torque of the proposed machine has already been reduced to a very low level, there would be expected practical difficulties of accurate measurement. Moreover, the 2-D and 3-D FEA models hypothesize perfect manufacture and assembly of the machine. However the prototype machine

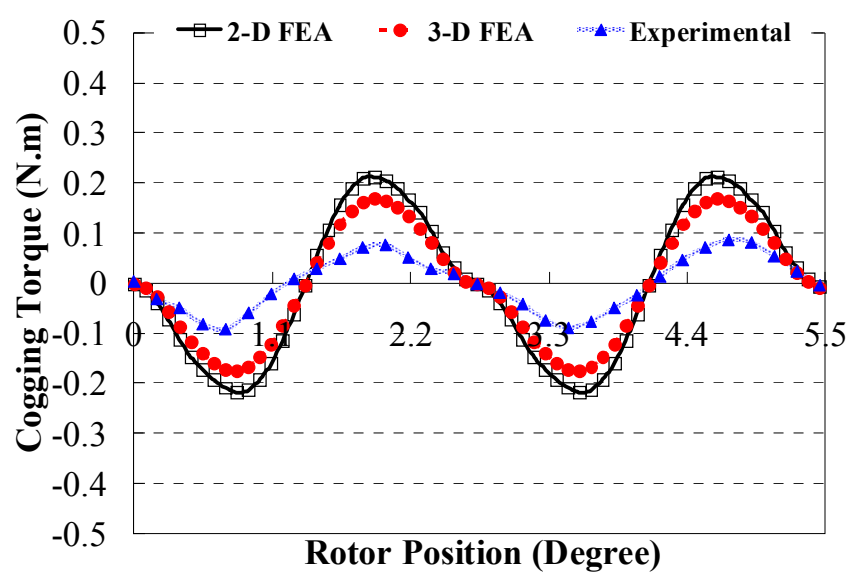

(a)

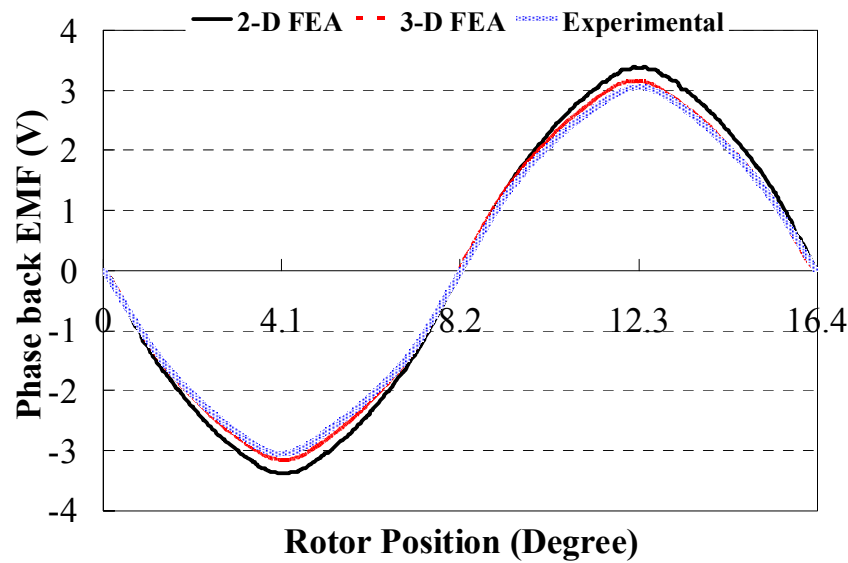

(b)

Fig. 12. Cogging torque and phase back EMF waveforms of the prototype machine from 2-D, 3-D FEA estimations and experimental measurement, (a) cogging torque profiles, (b) phase back EMF profiles.

TABLE II

OPEN-CiRCUIT COGgING TORQUe AND PHASE BACK EMF CHARACTERISTICS FROM 2-D, 3-D FEA AND EXPERIMENTAL MEASUREMENT

\begin{tabular}{|c|c|c|c|c|}
\hline \hline \multicolumn{2}{|c|}{ Characteristics } & 2-D FEA & 3 -D FEA & Experimental \\
\hline \multicolumn{2}{|c|}{ P-P Cogging Torque } & $0.43 \mathrm{~N} \cdot \mathrm{m}$ & $0.34 \mathrm{~N} \cdot \mathrm{m}$ & $0.18 \mathrm{~N} \cdot \mathrm{m}$ \\
\hline \multirow{2}{*}{$\begin{array}{c}\text { Phase back } \\
\text { EMF } \\
\text { Harmonics }\end{array}$} & Fundamental & $3.20 \mathrm{~V}$ & $3.05 \mathrm{~V}$ & $2.98 \mathrm{~V}$ \\
\cline { 2 - 5 } & Third & $0.0134 \mathrm{~V}$ & $0.0108 \mathrm{~V}$ & $0.0142 \mathrm{~V}$ \\
\cline { 2 - 5 } & Fifth & $0.0869 \mathrm{~V}$ & $0.0649 \mathrm{~V}$ & $0.0672 \mathrm{~V}$ \\
\cline { 2 - 5 } & Seventh & $0.0132 \mathrm{~V}$ & $0.0148 \mathrm{~V}$ & $0.0158 \mathrm{~V}$ \\
\hline \hline
\end{tabular}

would inevitably be subject to mechanical tolerances and assembly deficiencies. In particular, the machine has relatively complex stator with a high number magnet pieces, making it all the more difficult for the stator to be assembled to the desired stringent tolerances. Cogging torque could be very sensitive to those mechanical tolerances and deficiencies especially when it is minimized by geometric optimization. Nonetheless, the predicted and the experimental waveforms show that they essentially follow the similar variation and overall the agreements can be considered satisfactory. Furthermore, the phase back EMF waveform of the prototype measured at the rated speed of $120 \mathrm{rpm}$ is compared against the corresponding 2-D and 3-D FEA results as shown in Fig.10(b), which reveals that the experimental one is rather smaller than the predicted results, particularly the 2-D FEA one. To further investigate the phase back EMF, harmonic analysis has been carried out and the corresponding crucial phase back EMF 


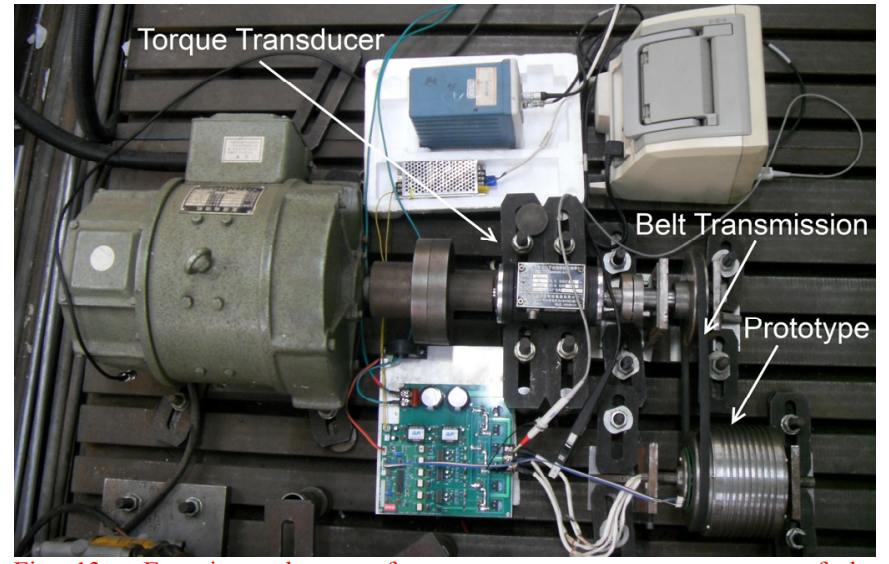

Fig. 13. Experimantal setup for average torque measurements of the prototype machines.

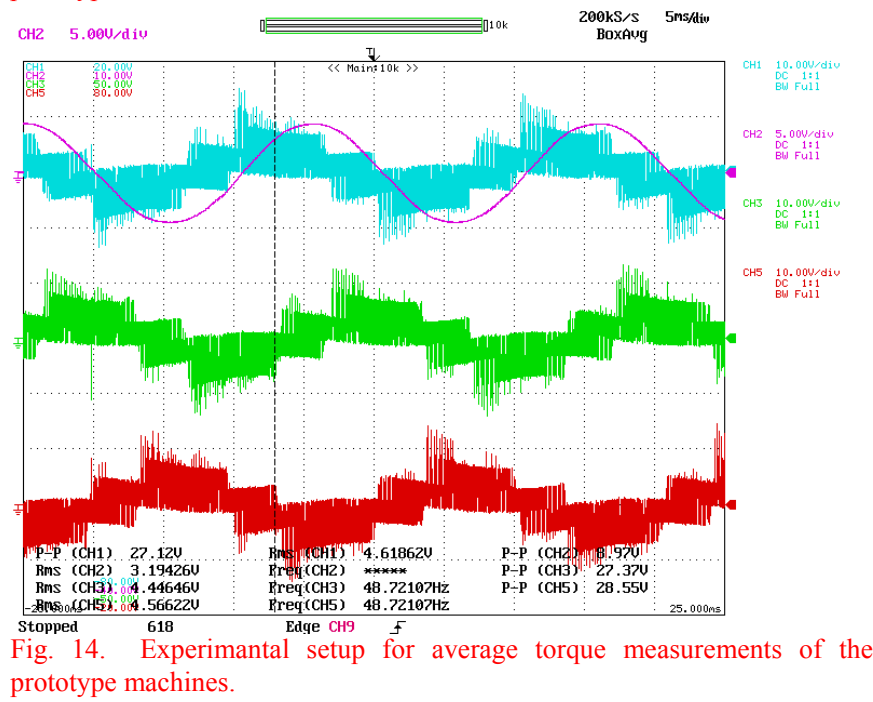

harmonics (fundamental, third, fifth, and seventh) are given in Table II. Generally, the back EMF is much less susceptible to mechanical defects and bench measurements than in the case of low-level cogging torque. The fundamental value of phase back EMF from experiment is $6.9 \%$ and $2.3 \%$ lower than the estimated ones from 2-D and 3-D FEA respectively. Moreover, the experimental amplitudes of other phase back EME harmonic components are in close agreements especially with the estimated ones. However, the 2-D FEA results deviate much more significantly from the experimental ones compared with the 3-D FEA ones due to the severe end effects. It can be also observed from the table that other harmonic components are relatively very small so that the phase back EMF profiles are essentially sinusoidal. That implies that the on load PM torque ripple of the prototype is somewhat suppressed. Overall, very good agreements have been achieved between the predicted and experimental phase back EMF results.

During the load tests, the prototype is powered by a voltage source inverter (VSI) with common space vector pulse width modulation (SVPWM) technique. However, the controller and load system of the experimental setup would make the experimental torque pulsations differ significantly from the predicted electromagnetic torque ripple results and it is impractical to decouple the controller induced torque ripple due to limitations of the experimental test rig. Moreover, it is

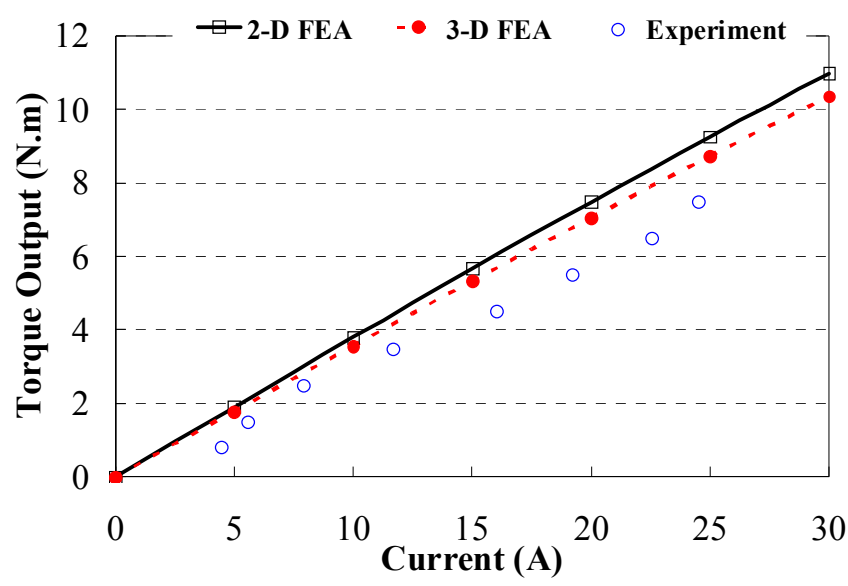

(a)

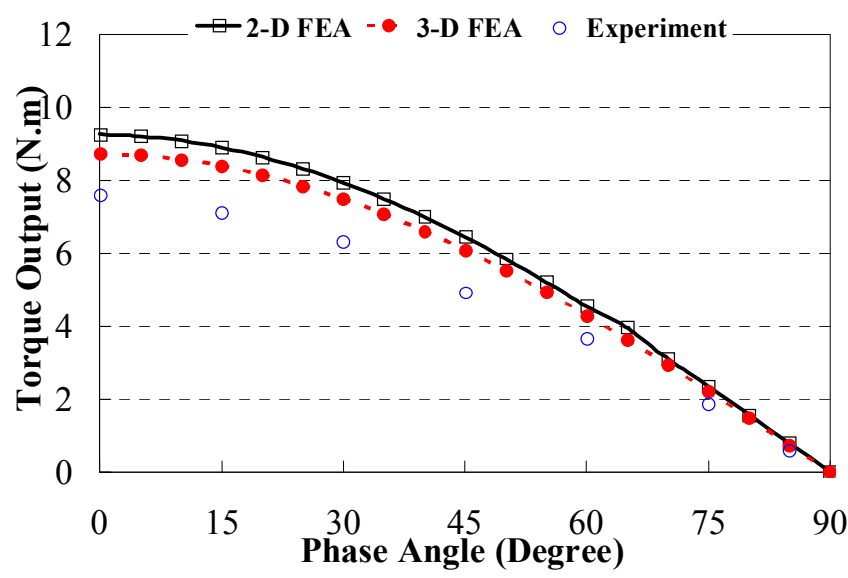

(b)

Fig. 15. Machine torque profiles from 2-D and 3-D FEA estimations and experimental measurement, (a) torque-current profiles with zero current phase angle, (b) torque-phase angle profiles with rated current amplitude.

physically impossible to segregate the torque components during the experimental tests. Therefore, only the overall average torque values of the prototype are measured for general validations. The average torque values of the prototype with various current excitations and current phase angle of zero from the experiments are first derived and compared with the 2-D and 3-D FEA ones in Fig.11(a). The average toque values with various current phase angles and rated current excitation are measured and illustrated with the predicted ones in Fig.11(b). On the whole, relatively large discrepancies in the average torque are observed between the results from the 2-D and 3D FEA models and those from experiments, which comport well with the corresponding ones of the fundamental phase back EMF. In addition to the previous explanations for open circuit results, the mechanical transmission in the testing setup would incur considerable friction losses and hence contribute extra negative errors to the experimental results. Taking all those factors into account, it is reasonable to conclude that the average torque profiles from the experimental measurements are in broad agreements with the corresponding 2-D and 3-D FEA ones.

\section{CONCLUSION}

The comprehensive analysis on the torque characteristics of 
a 12/22 outer-rotor PMFS machine has been carried out. The 2-D FEA models together with frozen permeability techniques with are employed in order to decompose the output torque of the proposed outer-rotor PMFS machine into cogging torque, reluctance torque and permanent magnet torque. The comprehensive results have suggested that both the amplitude and phase angle of the phase current would have profound influences on not only the overall torque output and torque ripple but also the characteristics of the three torque components in the proposed machine. Furthermore, the 3-D FEA results have revealed that the end effects would potentially increase the torque ripple but inevitably reduce the PM flux linkages and hence the overall torque output in the machine. The experimental results from the open circuit and on load tests on the prototype have shown satisfactory agreements with the estimated ones by the 2-D and 3-D FEA models, and underpinned the findings of this study. Although the proposed torque segregation method has been performed on the outer-rotor PMFS machine, it is envisaged that this method can also be employed to investigate the torque characteristics of other PM brushless machine types.

\section{ACKNOWLEDGMENT}

The authors gratefully acknowledge Powersys solutions for supporting the FEA software package Jmag-Designer v12.

\section{REFERENCES}

[1] S. E. Rauch, and L. J. Johnson, "Design principles of flux-switching alternators," AIEE Trans., Power Apparatus Syst. Part III, vol. 74, no. 3, pp. 1261-1268, Jan. 1955.

[2] E. Hoang, A. H. Ben-Ahmed, and J. Lucidarme, "Switching flux PM polyphased synchronous machines," in Proc. $7^{\text {th }}$ Eur. Conf. Power Electron. Appl., Sep. 1997, vol. 3, pp. 903-908.

[3] Z. Q. Zhu and J. T. Chen, "Advanced flux-switching permanent magnet brushless machines," IEEE Trans. Magn., vol. 46, no. 6, pp. 1447-1453, Jun. 2010.

[4] Z. Q. Zhu, Y. Pang, D. Howe, S. Iwasaki, R. P. Deodhar, and A. Pride, "Analysis of electromagnetic performance of flux-switching PM machines by non-linear adaptive lumped parameter magnetic circuit model," IEEE Trans. Magn., vol. 41, no. 11, pp. 4277-4287, Nov. 2005.

[5] Y. Chen, Z. Q. Zhu, and D. Howe, "Three-dimensional lumped parameter magnetic circuit model for analyzing single-phase fluxswitching PM motor," IEEE Trans. Ind. Appl., vol. 44, no. 6, pp. 17011710, Nov./Dec. 2008

[6] E. Ilhan, B. L. J. Gysen, J. J. H. Paulides, and E. A. Lomonova, "Analytical hybrid model for flux switching permanent magnet machines," IEEE Trans. Magn., vol. 46, no. 6, pp. 1762-1765, Jun. 2010

[7] E. Ilhan, J. Paulides, L. Encica, and E. Lomonova, "Tooth contour method implementation for the flux switching PM machines," in Proc. Int. Conf. Elec. Mach., Sep. 2010, pp. 1-6.

[8] B. Gysen, E. Ilhan, K. Meessen, J. Paulides, and E. Lomonova, "Modelin of flux switching permanent magnet machines with fourier analysis," IEEE Trans. Magn., vol. 46, no. 6, pp. 1499-1502, Jun. 2010.

[9] Y. Cheng, C. Pollock, and H. Pollock, "A permanent magnet flux switching motor for low energy axial fans," in Proc. IEEE Ind. Appl. Soc. Annu, Meeting, Oct. 2005, vol.3, pp. 2168-2175.

[10] W. Xu, G. Le, T. Wang, X. Yu, J. Zhu, and Y. Guo, "Theoretical research on new laminated structure flux switching permanent magnet machine for novel topologic plug-in hybrid electrical vehicle," IEEE Trans. Magn., vol. 48, no. 11, pp. 4050-4053, Nov. 2012.

[11] J. Ojeda, M. G. Simoes, G. Li, and M. Gabsi, "Design of a flux switching electrical generator for wind turbine systems," IEEE Trans. Ind. Appl., vol. 48, no. 6, pp. 1808-1816, Nov./Dec. 2012.

[12] W. Fei, P. C. K. Luk, J. X. Shen, Y. Wang, and M. Jin, "A novel permanent-magnet flux switching machine with an outer-rotor configuration for in-wheel light traction applications," IEEE Trans. Ind. Appl., vol. 48, no. 5, pp. 1496-1506, Sep./Oct. 2012.

[13] M. Lin, L. Hao, X. Li, X. Zhao, and Z. Q. Zhu, "A novel axial field fluxswitching permanent magnet wind power generator," IEEE Trans. Magn., vol. 47, no. 10, pp. 4457-4460, Oct. 2011.

[14] J. T. Chen, Z. Q. Zhu, and D. Howe, "Stator and rotor pole combinations for multi-tooth flux-switching permanent-magnet brushless AC machines," IEEE Trans. Magn., vol. 44, no. 12, pp. 4659-4667, Dec. 2008

[15] S. Kayano, M. Sanada, and S. Mormoto, "Power characteristics of a permanent magnet flux switching generagor for a low-speed wind turbine," in Proc. Int. Power Electron. Conf., Jun. 2010, pp. 258-263.

[16] K. Lu, P. O. Rasmussen, S. J. Watkins, and F. Blaabjerg, "A new lowcost hybrid switched reluctance motor for adjustable-speed pump applications," IEEE Trans. Ind. Appl., vol. 47, no. 1, pp. 314-321, Jan./Feb. 2011.

[17] K. Lu, U. Jakobsen, and P. O. Rasmussen, "Single-phase hybrid switched reluctance motor for low-power low-cost applications," IEEE Trans. Magn., vol. 47, no. 10, pp. 3288-3291, Oct. 2011.

[18] W. Fei and J. X. Shen, "Novel permanent magnet switching flux motors," in Proc. Int. Universities Power Eng. Conf., Sep. 2006, pp. 729-733.

[19] T. Raminosoa, C. Gerada, and M. Galea, "Design considerations for a fault-tolerant flux-switching permanent-magnet machine, "IEEE Trans. Ind. Electron., vol. 58, no. 7, pp. 2818-2825, Jul. 2011.

[20] Y. Wang and Z. Deng, "A multi-tooth fault-tolerant flux-switching permanent-magnet machine with twisted-rotor," IEEE Trans. Magn., vol. 48, no. 10, pp 2674-2684, Oct. 2012.

[21] A. Zulu, B. C. Mecrow, and M. Armstrong, "Permanent-magnet fluxswitching synchronous motor employing a segmental rotor," IEEE Trans. Ind. Appl., vol. 48, no. 6, pp. 2259-2267, Nov./Dec. 2012.

[22] M. S. Islam, S. Mir, T. Sebastian, and S. Underwood, "Design considerations of sinusoidally excited permanent-magnet machines for low-torque-ripple applications," IEEE Trans. Ind. Appl., vol. 41, no. 4, pp. 955-962, Jul./Aug. 2005.

[23] W. Fei, P. C. K. Luk, J. X. Shen, and Y. Wang, "A novel outer-rotor PM flux-switching machine for urban electric vehicle propulsion," in Proc. $3^{\text {rd }}$ Int. Conf. Power Electron. Syst. Appl., May 2009, pp. 1-6.

[24] D. A. Staton, R. P. Deodhar, W. L. Soong, and T. J. E. Miller, "Torque prediction using the flux-MMF diagram in $\mathrm{AC}, \mathrm{DC}$, and reluctance motors," IEEE Trans. Ind. Appl., vol. 32, no. 1, pp. 180-188, Jan./Feb. 1996.

[25] N. Bianchi and S. Bolognani, "Magnetic models of saturated interior permanent magnet motors on finite element analysis," in Proc. IEEE Ind. Appl. Soc. Annu. Meeting, 1998, vol. 1, pp. 27-34.

[26] S. Williamson and A. M. Knight, "Performance of skewed single-phase line-start permanent magnet motors," IEEE Trans. Ind. Appl., vol. 35, no. 3, pp. 577-582,May/Jun. 1999.

[27] G. H. Kang, J. P. Hong, G. T. Kim, and J. W. Park, " Improved parameter modelling of interior permanent magnet synchronous motor based on finite element analysis," IEEE Trans. Magn., vol. 36, no. 4, pp. 1867-1870, Jul. 2000.

[28] J. A. Walker, D. G. Dorrell, and C. Cossar, "Flux-linkage calculation in permanent-magnet motors using the frozen permeabilities method," IEEE Trans. Magn., vol. 41, no. 10, pp. 3946-3948, Oct. 2005.

[29] J. Hu, J. Zou, and W. Liang, "Finite element calculation of the saturation dq-axes inductance for a direct drive PM synchronous motor considering cross-magnetization," in Proc. Int. Power Electron. Drive Syst. Conf., 2003, vol. 1, pp. 677-681.

[30] S.-Y. Kwak, J.-K. Kim, and H.-K. Jung, "Characteristic analysis of multilayer-buried magnet synchronous motor using fixed permeability method," IEEE Trans. Energy Convers., vol. 20, no. 3, pp. 549-555, Sep. 2005.

[31] K. Shirai, Y. Tokikuni, K. Shima, T. Fukami, R. Hanaoka, and S. Takata, "Causes of increase in the terminal voltage of a permanent-magnetassisted salient-pole synchronous machine," in Proc. Int. Electr. Mach. Syst., 2009, pp. 1-6.

[32] G. Dajaku and D. Gerling, "Magnetic radial force density of the PM machine with 12-teeth/10-poles winding topology," in Proc. IEEE Int. Electr. Mach. Drives Conf., 2009, pp. 1715-1720.

[33] J. K. Tangudu, T. M. Jahns, A. M. El-Refaie, and Z. Q. Zhu, "Segregation of torque components in fractional-slot concentratedwinding interior PM machines using frozen permeability," in Proc. IEEE Energy Convers. Congr. Expo., Sep. 2009, pp. 3814-3821. 
[34] W. Q. Chu and Z. Q. Zhu, "Average torque separation in permanent magnet synchronous machines using frozen permeability," IEEE Trans. Magn., vol. 49, no. 3, pp. 1202-1210, Mar. 2013.

[35] W. Q. Chu and Z. Q. Zhu, "On-load cogging torque calculation in permanent magnet machines," IEEE Trans. Magn., vol. 49, no. 6, pp. 2982-2989, Jun. 2013.

[36] V. Ruuskanen, J. Nerg, and J. Pyrhonen, "The effect of lamination stack ends and radial cooling channels on no-load voltage and inductances of permanent magnet synchronous machines," IEEE Trans. Magn., vol. 47, no. 11, Nov. 2011.

[37] Z.Q. Zhu, "A simple method for measuring cogging torque in permanent magnet machines," in Proc. IEEE Power Energy Soc. Gen. Meet., Jul. 2009, pp.1-4. 